\title{
PERCEPTUAL SPATIAL DIFFERENTIATION OF LJUBLJANA
}

\author{
Marko Krevs \\ Department of Geography, Faculty of Arts, University of Ljubljana, \\ Aškerčeva 2, 1000 Ljubljana, Slovenia. \\ e-mail: marko.krevs@ff.uni-lj.si
}

\begin{abstract}
Geographical studies of human perception of places at local scale are usually aimed at better understanding of human spatial perception and knowledge about the places, and of using this knowledge in spatial decision-making or spatial behaviour. Our focus on the first part of these general research aims is presented based on a case study, revealing how residents of the Municipality of Ljubljana perceive and value neighbourhoods of "their" municipality at the beginning of the century ${ }^{1}$.
\end{abstract}

Key words: topophilia, topophobia, spatial differentiation, environmental perception, urban geography, Ljubljana.

Perception of neighbourhoods is understood in a manner of humanistic geography as emotional, positive or negative, attachments to neighbourhoods as places. Concepts like experience of place, sense of place, attachment to places, topophilia and topophobia in a broad sense, as understood by Tuan (1974, 1977), Eyles (1985), Entrikin (1991), Relph (2002), are used or referred to in the study. But our approach is not really based on an "in-depth kind of research" characteristic for humanistic geography. Only some terms and their understanding and interpretation are borrowed from this branch of (or approach to) human geography. Another important conceptual spring of our research is the linking of perception of the "real world" to (potential) spatial behaviour and eventually changing the physical and social environments, as proclaimed by behavioural geography.

Our broader aim is to follow changes of perceptual spatial differentiation of Ljubljana in parallel with, and in relation to several contemporary spatial processes going on in the area, like gentrification, urban sprawl, spatial changes in urban functions and socialeconomic segregation. Since this is only the first in the planned series of studies, bigger

\footnotetext{
${ }^{1}$ Questionnaire survey has been carried out in 2001 by the 3rd year students of geography at Department of
} Geography, Faculty of Arts, University of Ljubljana (Atelšek et al., 2001). 
attention has been given to some methodological questions, related also to longitudinal comparability of the results, discussed later in the paper.

Beside consideration of basic methodological questions, only some basic answers to the following questions are presented:

- is there an evident difference in intensity of perception of positive and negative aspects of the neighbourhoods?

- are there any strong correlations of studied aspects of perception of the neighbourhoods to some social-economic characteristics and processes in the neighbourhoods?

- what combinations of studied attachments to places, "love", "hate" and "fear", are found related to individual neighbourhoods?

\section{MEASURING PERCEPTIONS}

Initial methodological decisions in the study were related to the technique of collecting the perceptual information, including spatial division of the municipality into neighbourhoods, sampling technique for selection of the respondents, and questionnaire design. Interpretation of the collected information was supported by appropriate aggregations of data, classification of neighbourhoods from the point of view of the intensity of their perception, analysis of correlations between "perceptual information" and selected other characteristics of the neighbourhoods, and mapping perceptual spatial differentiations of the Municipality of Ljubljana.

»Neighbourhoods« are defined on the basis of subdivision of city districts (mestne četrti). The latter were officially introduced just recently, and are quite bigger than former local communities (krajevne skupnosti) that functioned as local territorial division for several decades. As a consequence, some of the districts are composed of very diverse local communities that have gained some »generally known« local identity, expressed also by distinctive names. Such districts are divided into smaller spatial units, we call them neighbourhoods, with at least some local identity and relative social-economical homogeneity. Recognizable neighbourhoods are among the methodological conditions in the study. On the other hand, it is clear that it cannot be presumed that all individuals answering the questionnaires know all neighbourhoods, or that they even have systematically developed attitudes for them².

Sampling of the 540 respondents has been carried out in two stages. From every of the 27 neighbourhoods a quota sample of adult respondents has been taken, roughly corresponding to local gender and type of housing structure.

Questionnaire survey is viewed as a principal method for collecting (spatial) behavioural information by more "positivistically oriented« researchers (e.g. Robinson, 1998,

\footnotetext{
${ }^{2}$ Neighbourhoods defined by planners, politicians, or researchers, are intellectual or political concepts, and as such not necessary perceived as place - with identity of any meaning for their lives - by locals or »outsiders«. Besides, some neighbourhoods lack visual or intrinsic prominence or identity, positive or negative, and can be referred to as "placeless" (Relph, 2002, 913), "faded and discoloured" (Hiss, 1990, xv), especially by non-local respondents.
} 
377), but given little confidence to reveal anything but superficial, general information about human attitudes by more »epistemologically and ontologically enlightened « human geographers (e.g. Hoggart, Lees, Davies, 2002, 169-200). Since our intentions with the questionnaires do not go further than expected by the latter group of geographers, our main concerns are to minimise the main potential biases of the method.

Answering to questionnaires like ours, respondents mix both, attitudes originating from their own experiences, as »insiders« or »outsiders«, of individual neighbourhoods, and »constructed attitudes«, based mostly on external information. The first type of attitude is based mainly on distinctive emotional or rational bonds to individual neighbourhoods or locations within them. The second type of attitudes is basically »constructed for the purpose «, using any information available in respondents memory and to his mind at the moment of answering to the questionnaire. This type of evaluations and judgements, discharged by the mind, are seldom original and tend to be clichés (Tuan, 1977 (2002), 144). Eyles (1985) has found out considerable variations in type and intensity of sense of place, depending on such things as familiarity, detachment, social status, gender and self-consciousness. Well aware of these methodological traps, the questions were designed in the following way:

- $\quad$ respondents had to pick three of the neighbourhoods from Municipality of Ljubljana that - by their opinion - suit best to a given characteristic; majority of respondents are supposed to be able to report their perception of several neighbourhoods; picking three of them instead of only one should just make the task easier, as the ranking they use is not so restrictive;

- $\quad$ only three - by our opinion very unambiguous - aspects of perceptions of neighbourhoods have been studied, demanding respondents to choose the neighbourhoods that are the most attractive for living, the least attractive for living, and the most unsafe; in terms of topophilia and topophobia, the answers to the first question show "love for a neighbourhood", answers to the second question "hate of a neighbourhood", and answers to the third question "fear of a neighbourhood".

"Basic" territorial aggregation of collected responses allows us to study "intensity"3 of perception, defined by proportion of respondents choosing individual neighbourhoods from a given aspect of perception. Other possibilities, not presented here, allow us to study e.g. ratio of external to internal "votes" for the neighbourhood, or differences in spatial perceptual differentiation of the municipality due to gender of respondents.

Classifications of neighbourhoods based on intensity of their perception from a given aspect are used to simplify the presentation of the results, and to construct more complex "perceptual types" of neighbourhoods based simultaneously on all three studied aspects of perception. Criteria used to define low, medium or high intensity of perception from a given aspect, differ from one aspect to another due to their adjustment to different ranges and frequency distributions of intensities of studied perceptions. The mentioned complex percep-

\footnotetext{
${ }^{3}$ Intensity of perception from the point of view of local communities or some spatial aggregate of population, in our case perception of a sample of the population of Municipality of Ljubljana.
} 
tual types of neighbourhoods are defined on basis of existing combinations of the three studied intensities of perception for individual neighbourhood. Only "intensive perceptions" (showing high or at least medium intensity of perception) are taken into account in description (naming) of the types.

Pearson correlation coefficients are taken as a rough estimate of correlation between "perceptual information" and selected socio-economic characteristics of the neighbourhoods. These estimates help us to generally interpret relations between perceptions or attitudes to neighbourhoods ("perceived neighbourhoods"), and some aspects of "objective circumstances" in the neighbourhoods ("objective neighbourhoods").

And finally, mapping perceptual spatial differentiations of the Municipality of Ljubljana help us to spatially present and interpret our findings.

\section{LOVE, HATE AND FEAR OF NEIGHBOURHOODS}

On the basis of comparisons of the three maps of intensity of perception (figures 1,2 and 3), and the tables of spatially aggregated data, we can extract some general findings. Positive attitudes to neighbourhoods are considerably more evenly spatially distributed, characterized by smaller spatial variability of the intensity of perception, than the negative ones. "Rožna dolina", the most often selected as neighbourhood attractive for living, was "chosen" by $30 \%$ of respondents, "Nove Fužine" as the most non-attractive neighbourhood for living by $51 \%$ of respondents, and the same neighbourhood as the most unsafe by $71 \%$ of respondents. At least a partial explanation of this finding could be a wider range of factors influencing positive perceptions, which are probably more often based on respondent's own experience. On the other hand the negative perceptions may be based on a single (or a small number of) criterion, possibly »borrowed « from general public opinion and clichés. Selecting "the worst" neighbourhoods is practically always "pointing at others", while all the neighbourhoods, even "the worst" by general opinion, are selected as "attractive for living" at least by some locals. The negative stereotypes about the characteristics of the neighbourhoods tend to be much stronger, spatially more concentrated to certain neighbourhoods than the positive ones. And from the perspective of distance to selected neighbourhoods from "home neighbourhood", the positive attitudes tend to have more spatially autocorrelated distribution than the negative ones.

Pearson correlation coefficients in general show low correlations between the ("subjective") perceptions and "objective" socio-economic characteristics of the neighbourhoods. This in a way supports the behavioural geographical claims of a usually strong distinction between the "objective environment" and the "behavioural environment", constructed from non-perfect and subjectively filtered information. Moderate correlations (absolute value of $r>0.5$ ) are found between the:

- proportion of respondents choosing a neighbourhood as attractive for living, and the size of housing compared to number of residents, and taxable income per capita; 
Figure 1: The perceived most attractive neighbourhoods for living.

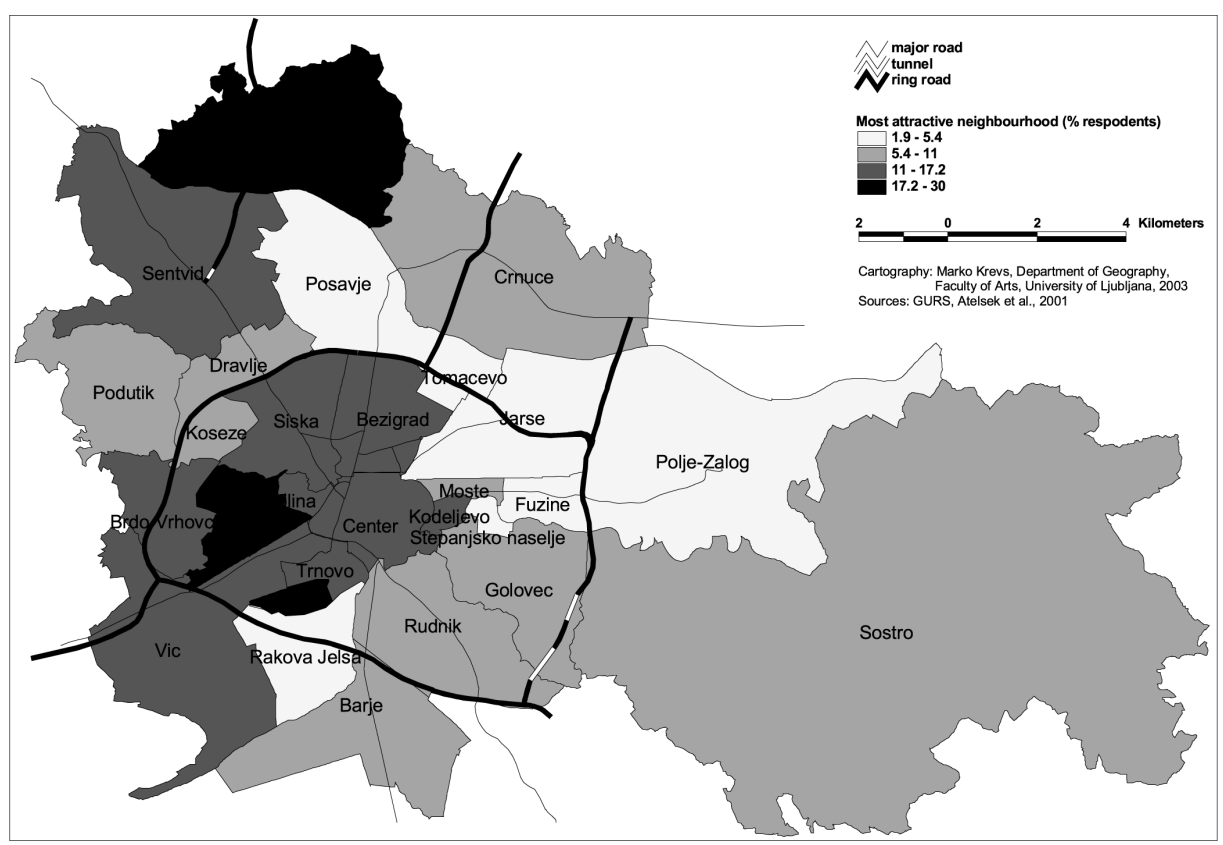

Figure 2: The perceived most non-attractive neighbourhoods for living.

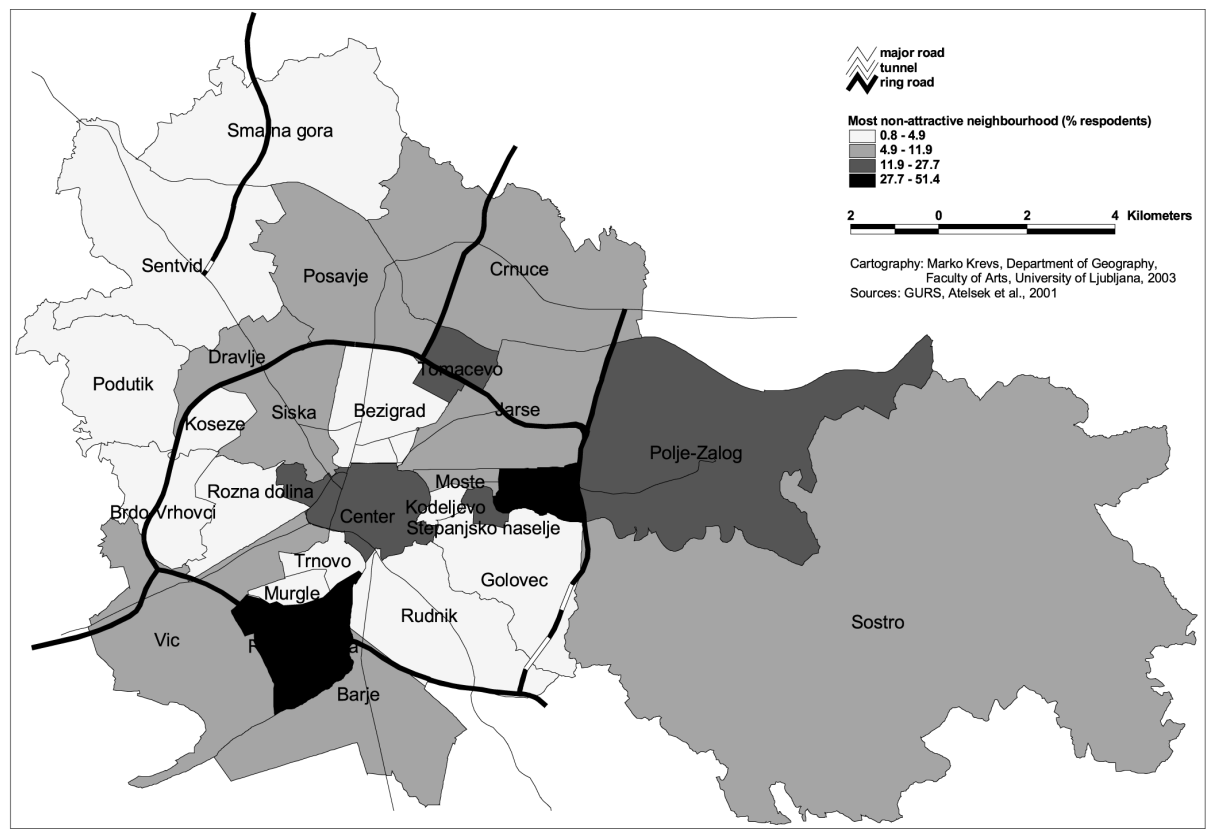


Figure 3: The perceived most unsafe neighbourhoods.

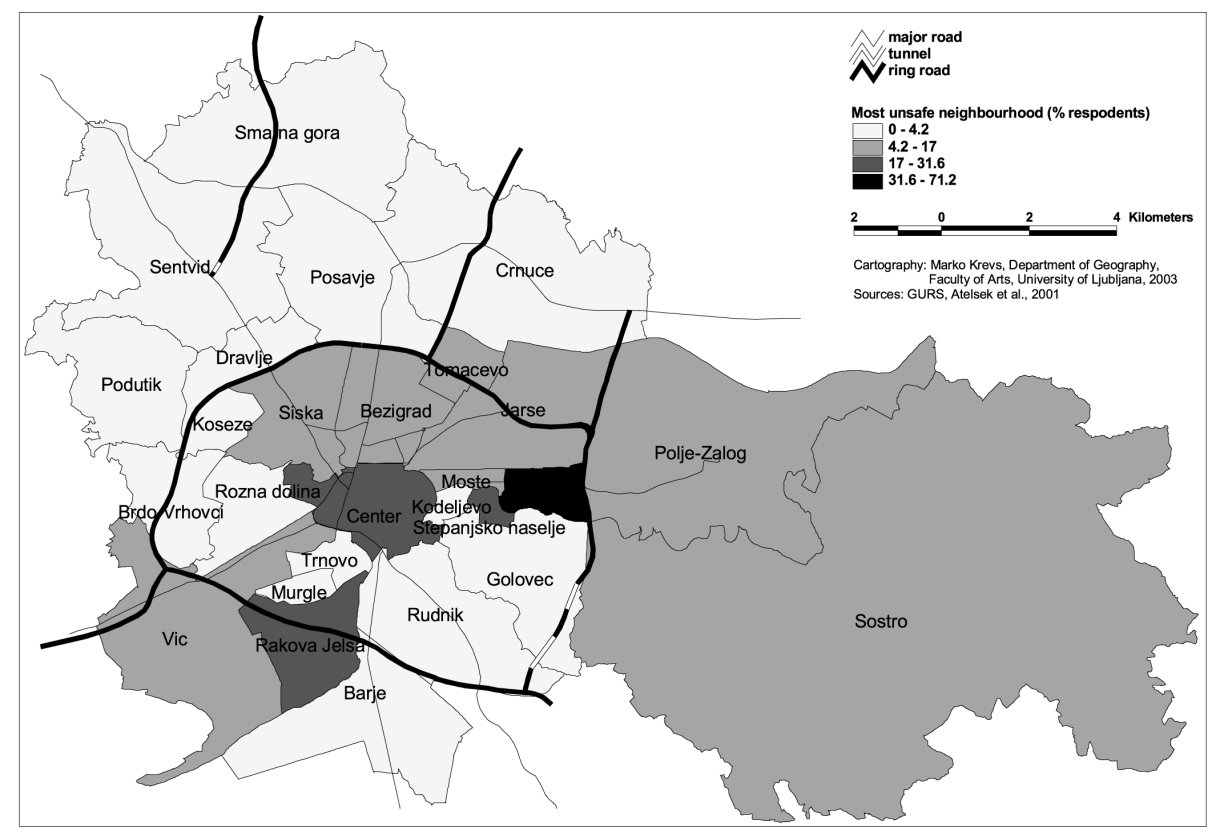

- proportion of respondents choosing a neighbourhood as non-attractive for living, and the proportion of "non-Slovenian" population, and size of housing compared to number of residents;

- proportion of respondents choosing a neighbourhood as unsafe, and the proportion of "non-Slovenian" population.

The limited selection of variables presenting the characteristics of neighbourhoods in the analysis does not allow us to draw general conclusions about the criteria of neighbourhood perception. But we can notice a shift from more "materialistic" values behind the positive perceptions towards more "nationalistic" ones behind the perceptions of non-attractive and unsafe neighbourhoods. Obviously, at least data about criminality in the studied neighbourhoods should enable us to interpret more reliably the perception of unsafe neighbourhoods.

On the other hand, no significant correlation has been found between any of the "perceptual variables" and the index of population change, density of population or size of households. While the last two may be partly explained by diversified residential preferences, the first is - at least for a moment - a bit surprising. But explanation might be quite simple: middle- or higher-class residents often move to positively perceived neighbourhoods (e.g. "Murgle"), and lower-class residents to less favourable neighbourhoods (e.g. "Tomačevo"), so both "types" of neighbourhoods may be characterized by population increase. On the other hand, stagnation or even decreasing of the population may be found in some very positively (e.g. "Trnovo", "Center", "Rožna dolina"), or very negatively perceived neighbourhoods (e.g. "Rakova jelša”, "Štepanjsko naselje”, "Nove Fužine”). 
The most complex presentation of perceptual spatial differentiation in our study is the complex typology of neighbourhoods based on all three aspects of neighbourhood perceptions (table 1, figure 4). First finding is that only a small part of studied neighbourhoods are perceived intensively from any of the studied aspects. "Poorly perceived" neighbourhoods (white on the map) are not necessarily "placeless" (term as used by e.g. Entrikin, 1991, Relph, 2002) - missing visual and perceptual identity and particularity. They may simply be perceived as "non-relevant" from the studied aspects by majority of respondents.

Table 1: Characteristics of complex perceptual types of neighbourhoods based on combinations of intensive perceptions - in terms of topophilia and topophobia.

\begin{tabular}{|l|l|}
\hline $\begin{array}{l}\text { Perceptual type } \\
\text { of neighbourhood }\end{array}$ & Some characteristics of neighbourhoods of certain type \\
\hline Love & $\begin{array}{l}\text { different types of »good « social areas close to the centre, } \\
\text { and one suburban neighbourhood }\end{array}$ \\
\hline love \& some fear & socially mixed, neighbouring to the city centre \\
\hline love \& hate \& fear & $\begin{array}{l}\text { city centre, mixed but in average "good" social-economic } \\
\text { characteristics }\end{array}$ \\
\hline hate \& fear \& some love & socially mixed suburban area \\
\hline hate \& fear & $\begin{array}{l}\text { biggest area of illegal housing and concentration of »non-Slovenians «, } \\
\text { and two big multi-family housing neighbourhoods }\end{array}$ \\
\hline hate \& some fear & former rural, now suburban area with relatively poor social structure \\
\hline
\end{tabular}

Note: all other neighbourhoods are perceived by medium or low intensity of all three studied aspects.

Figure 4: Topophilia and topophobia of the neighbourhoods.

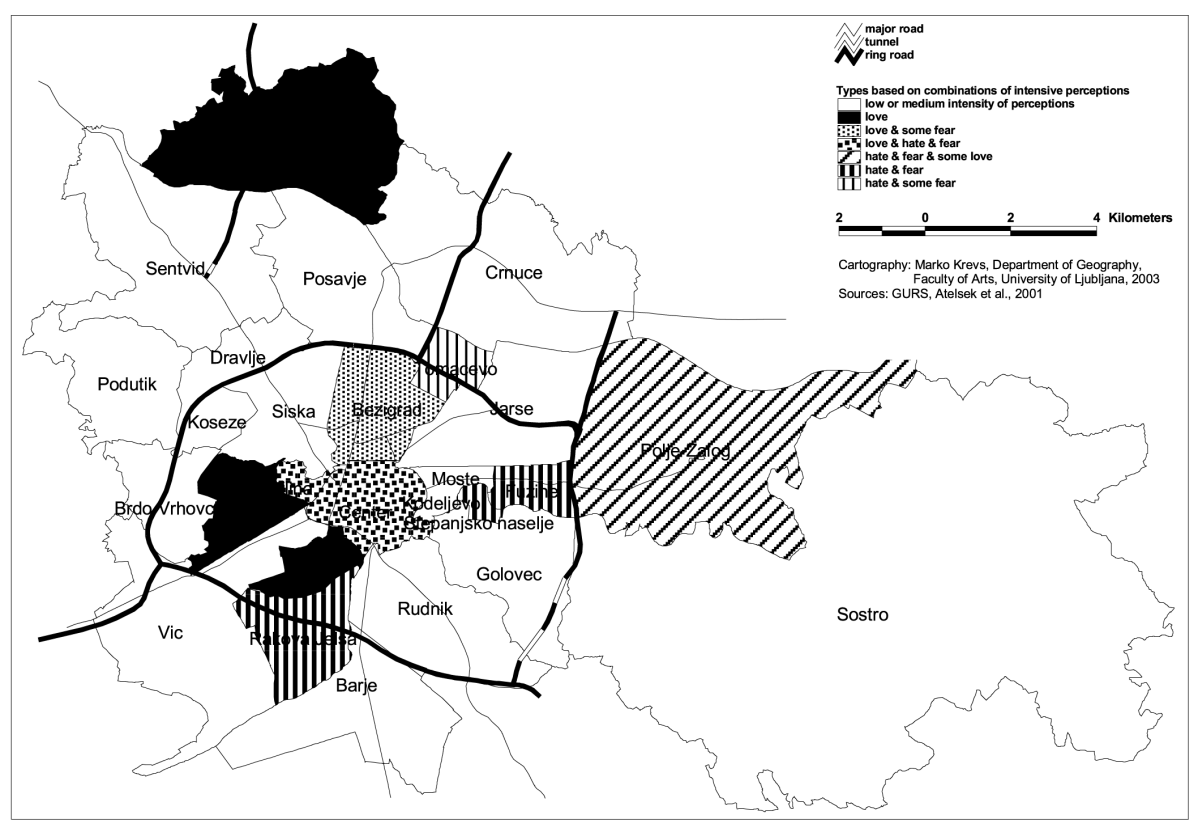


Three "kinds of types" (of combinations of intensive perceptions) of neighbourhoods are found. Two "kinds" include "pure" types, based on exclusively positive ("love") or negative perceptions ("hate" and "fear", "hate" and "some fear"). The only a bit surprising among those is the intensive positive perception of neighbourhood "Šmarna gora", suburban community with average social-economic structure at the northern outskirts of the municipality, experiencing second highest growth of population in the last decade among the studied neighbourhoods. Other neighbourhoods of these kinds (positively or negatively perceived) are much closer to the city center.

The third kind of perceptual types are based on combinations of positive and negative perceptions. These mixtures clearly demonstrate complexness of human spatial perception, and are by no means surprising. The most extreme case, neighbourhood "Center", is perceived intensively from all the three studied aspects: "loved", "hated" and "feared". The first two are usually not combinable at the level of individual respondents, mostly due to substantial differences in residential preferences, and can only be found on an aggregated level. The other two combinations ("love" and "fear", or "hate" and "fear") are quite expected, could be explained "objectively", and are found also in other neighbourhoods of these "mixed" types ("Bežigrad", "Tomačevo", "Polje-Zalog").

\section{CONCLUSIONS}

The planned longitudinal study of spatial changes of perceptual differentiation of the Municipality of Ljubljana should allow us to study temporal variability of such differentiation, its sensibility to certain processes in "objective environment" and in changes of value systems, ways of living, spatial behaviour. To keep the results comparable, the method should be kept "standardized". But the approach presented here is general and superficial, especially if judged from a point of view of its application in planning, real-estate evaluation, or research with more specific aims. To improve our knowledge about perception of neighbourhoods, and its relation to "real" spatial behaviour and consequent traces in the landscape, as well as the applicability of that knowledge, the following steps could be taken:

- more control variables in the questionnaires would allow us to study perception of subgroups of the sample of respondents, e.g. gender, social-economic status, housing type; to achieve this, sample size will probably have to be enlarged;

- more, and less arbitrarily chosen indicators of "objective" environment and processes in the neighbourhoods should be used to improve the interpretation and understanding of the their interrelations with perception of neighbourhoods;

- a combination of "standardized" questionnaire as in the presented study with in-depth interviews or questionnaires to study context, or factors of individual perceptions (in our further study such a complementary information will be taken from Kodre et al., 2000);

- $\quad$ studies of relations of perceptions to "real", concretely defined spatial situations, decisions or behaviour, e.g. selecting place of residence, investments, real-estate evaluation. 
Some already running research projects, studying e.g. urban sprawl, real-estate evaluation, urban landuse changing, spatial changes in level of living/ quality of life, in the Municipality of Ljubljana or wider region, could gain some interpretational power from this research. But an interesting "true challenge" for researchers, planners and spatial decision makers, could be development and use of such kind of knowledge, with an aim to identify and improve the neighbourhood's identity (image).

\section{Sources and literature}

Atelšek, G., Berdavs, J., Fegic, D., Kociper, M., Kolander, A., Pokorn, J., Tisu, M., 2001: Topofobne in topofilne predstave o soseskah v Mestni občini Ljubljana. Students' research report and database. Oddelek za geografijo, Filozofska fakulteta, Ljubljana; 7.

Entrikin, N., 1991: The betweenness of place. The Johns Hopkins University Press, Baltimore.

Eyles, J., 1985: Senses of place. Silverbrook Press, Warrington.

Hoggart, K., Lees, L., Davies, A., 2002: Researching human geography. Arnold, London.

Holloway, L., Hubbard, P., 2001: People and place. The extraordinary geographies of everyday life. Pearson Education Limited, Edinburgh Gate, Harlow.

Kodre, L., Jakopin, A., Caf, N., Viskovič, A., 2000: Življenjske razmere v Ljubljani. Skupno poročilo študentov 1. letnika pri predmetu Geografija poselitve v študijskem letu 1999-2000 (mentor M. Krevs). Compendium of students' research reports. Oddelek za geografijo, Filozofska fakulteta, Ljubljana, 50.

Relph, E., 2002: Place. In: Douglas, I., Huggett, R., Robinson, M. (editors), Companion En-cyclopedia of Geography. The environment and Humankind. Routhledge, London; 906-922.

Robinson, G.M., 1998: Methods \& techniques in human geography. John Wiley \& Sons. Chichester.

Tuan, Y.-F., 1977 (9th reprint 2002): Space and place, The perspective of experience. University of Minnesota Press, Minneapolis.

Tuan, Y.-F., 1974 (Morningside Edition 1990): Topophilia, A Study of Environmental Perceptions, Attitudes, and Values. Columbia University Press. 